\title{
Research on Present Situation and the New Technology About Reinforcement in Collapsible Loess Foundation Inside Tunnels
}

\author{
Zhao Yonghu ${ }^{1,}$, , Han Kan ${ }^{2}$, Jiang Yuhua ${ }^{1}$, Mi Weijun ${ }^{1}$, Xue Chunxiao ${ }^{1}$, Wu Xiaopeng ${ }^{3}$ \\ ${ }^{1}$ Northwest Research Institute Co., Ltd. of China Railway Engineering Corporation, Lanzhou, China \\ ${ }^{2}$ China Raliway Academy Co., Ltd of China Railway Engineering Corporation, Chengdu, China \\ ${ }^{3}$ College of Civil Engineering and Architecture, Jiaxing University, Jiaxing, China
}

Email address:

253280321@qq.com (Zhao Yonghu),36230418@qq.com (Xue Chunxiao)

${ }^{*}$ Corresponding author

\section{To cite this article:}

Zhao Yonghu, Han Kan, Jiang Yuhua, Mi Weijun, Xue Chunxiao, Wu Xiaopeng. Research on Present Situation and the New Technology About Reinforcement in Collapsible Loess Foundation Inside Tunnels. Engineering and Applied Sciences. Vol. 6, No. 2, 2021, pp. 33-40. doi: $10.11648 /$ j.eas.20210602.11

Received: March 17, 2021; Accepted: March 26, 2021; Published: April 16, 2021

\begin{abstract}
The tunnel foundations treatment is the key and difficult point of the research of the tunnel in collapsible loess areas. The characteristics and advantages of the common foundations treatment technology for tunnels of loess areas are summarized in this paper, at the same time, the characteristics of a new technology for the non-vibration compaction treatment technology developed by the Northwest Research Institute Co., Ltd. of China Railway Engineering Corporation are introduced, which is suitable for the foundation reinforcement treatment of the tunnel in collapsible loess areas. Through the field experiment of base treatment of high-speed railway tunnel of the Baoji-Lanzhou High-Speed Railway Passenger Dedicated Line, it is demonstrated that the new non-vibration compaction machine has the advantages of convenient movement, controllable treatment effect, miniaturization, low cost and so on. The advancement and maneuverability are verified from the soil compaction coefficient between piles and the change law of collapsibility of the soil between piles under the different pile spacing conditions. The research results can provide new techniques and methods for the foundation reinforcement treatment of the tunnel of small space, strictly controlling construction vibration in collapsible loess areas.
\end{abstract}

Keywords: Tunnel, Loess Foundation, Reinforcement, No Vibration Compacting

\section{Introduction}

With the vigorous construction of Chinese railways and expressways and the rapid promotion of the "the Belt and Road" national strategy, the numbers and the scales of railways and highway tunnels of the project that have been built and under construction in the northwestern loess areas are unprecedented. Reasonable treatment of the foundations, improvement of bearing capacity and controlling of post-construction settlement and deformation have become the key and difficult points of tunnel construction, which are essential to ensure the safety operation of the tunnels. At present, many scholars have carried out a lot of research on the reinforcement treatment of collapsible loess tunnel foundations and fruitful results have been achieved. Wang xindong [1] took the Fenghuangling Tunnel of ZhengzhouXi'an High-Speed Railway Passenger Dedicated Line as an example, using the impact compaction cement-soil pile method to strengthen the collapsible loess foundation, which has a better effect in reducing the collapsibility of the loess at the tunnel foundations. Tree root piles were applied to treating the foundations of the Xinxiaozegou tunnel on the Shenshuo Railway and the influence of the material ratio, pile length, pile spacing, pile reinforcement and other factors on the bearing capacity of a single pile was analyzed by Liu dagang [2]. The types of diseases and their main causes of the foundations of heavy-duty railway tunnels was analyzed and then the treatment principles for the foundations of heavy-duty railway tunnels was determined by Li li [3]. The foundation treatment measures, waterproofing and structural measures of 
the tunnel foundation of Baoji-Lanzhou High-Speed Railway Passenger Dedicated Line were systematically summarized such as CFG piles, lime-soil compaction piles, rotary jet grouting piles or powder jetting piles, strong Measures such as ramming method or replacement method by $\mathrm{Fu}$ wei [4], the choice of Treatment measures was depended on the thickness of the collapsible soil layer. The calculation method of the vertical compressive stress of the foundation soil under the tunnel foundations for the loess foundation of different buried depths in the tunnel project was explored by Fan wen [5]. The collapsibility and stress conditions of the loess tunnel foundations were proposed and the loess tunnel foundations mechanical model was summarized by Li guoliang [6]. The influence of groundwater and cement-soil compaction pile reinforcement on the stability of the loess tunnel foundations of Zhengzhou-Xi'an High-Speed Railway was analyzed by using a numerical simulation method by CHen fujiang [7]. The non-vibration compaction equipment developed by China Railway Northwest Research Institute was conducted field tests in Zhengzhou-Xi'an High-Speed Railway by Sun bing [8], and the results showed that the developed non-vibration compaction pile equipment has good pile forming performance and has good applicability in the reinforcement of loess tunnel foundations.

The typical characteristics of new loess are the existence of large pores and collapsibility in contact with water. During tunnel excavation, the untreated collapsible loess foundations arch foot will have obvious stress concentration, so that the stress is far greater than the allowable bearing capacity, which will result in increased compression deformation and increased sinking of the arch foot. Improper water use during the construction period or failure of the waterproof and drainage measures during the operation period may cause significant collapse and deformation of the untreated loess under the foundation, and result in cracks in the lining structure and uneven settlement of the foundations, which indirectly affects the construction and threatening for the safety operation of the loess tunnel.

In view of this, the reinforcement treatment methods and their advantages and disadvantages of the railway and highway tunnel foundations in the loess area were summarized and then the basic structure and stress characteristics of the non-vibration compactor and compactor were introduced in this paper. The practical application effect of the non-vibration treatment technology for the collapsible loess tunnel foundations was analyzed by the field test of high-speed railway tunnel base reinforcement. The research results can provide scientific guidance and reference for the application of substrate treatment technology for high-speed railways and highway tunnels in the loess area.

\section{Analysis of Processing Methods and Their Advantages and Disadvantages}

In recent years, a large number of railway and highway tunnels in the loess areas has been built in China, and the tunnel excavation method mainly adopts the CD method or the CRD method [9]. The commonly used treatment methods for collapsible loess foundations mainly include: replacement cushion method, heavy hammer compaction method, compaction method, rotary grouting pile method, root pile method, and column hammer punching and expanding pile Method, blasting method, chemical reinforcement method and so on in geotechnical engineering other than tunnels. Because of the higher requirements and stricter foundation settlement controlling standards of tunnel engineering quality for High-speed railways, free vibration, limited work space, cumbersome work procedures should be considered in construction, so jet grouting pile method, replacement cushion method, and impact compaction method has become the main application method of tunnel foundation treatment in the loess area [9].

\subsection{Jet Grouting Pile Method and Its Advantages and Disadvantages}

The jet grouting pile is to spray the grout from the nozzle into the soil using a grout pipe, so that most of the soil particles are redistributed after being stripped from the soil. The soil particles and the grout are stirred and mixed and then arranged and rearranged according to a certain proportion of the grout and soil. It is condensed into a whole consolidation body, and a small part of the soil particles are brought out of the soil surface with the slurry. According to the rotation mode of the nozzle, the shape of the consolidated body is cylindrical, wall-like, and so on. The foundations of Dayoushan Tunnel were treated by jet grouting pile method and the scheme is shown in Figure 1.

The main advantages of using the jet grouting pile method in the collapsible loess tunnels are that the technology is relatively mature, the reinforcement quality can be guaranteed, and the long-term stability is good. The disadvantages of using the jet grouting pile method in the collapsible loess tunnels are that the working environment in the tunnel is poor, the construction machinery is expensive, existing cross-effects with the tunnel excavation and high project cost. In addition, the collapsibility of the loess between the piles is difficult to completely eliminate, and the treated foundation still has a safety hazard of collapsibility and deformation. Furthermore, the grout is difficult to control, which will cause secondary pollution to the tunnel construction environment, and cause additional collapsible deformation of the loess at the base of the tunnel, which affects the safety construction of the loess tunnel.

\subsection{The Replacement Cushion Method and Its Advantages and Disadvantages}

The replacement cushion method refers to the treatment method of digging out shallow soft soil or bad soil, backfilling qualified filler, and layered rolling or ramming compaction. The replacement cushion method can effectively improve the bearing capacity of the foundation soil, and partially eliminate or completely eliminate the collapsibility of the soil. Figure 2 is a schematic diagram of cement-soil replacement treatment 
for the foundation of the entrance of Huanglongcun Tunnel.

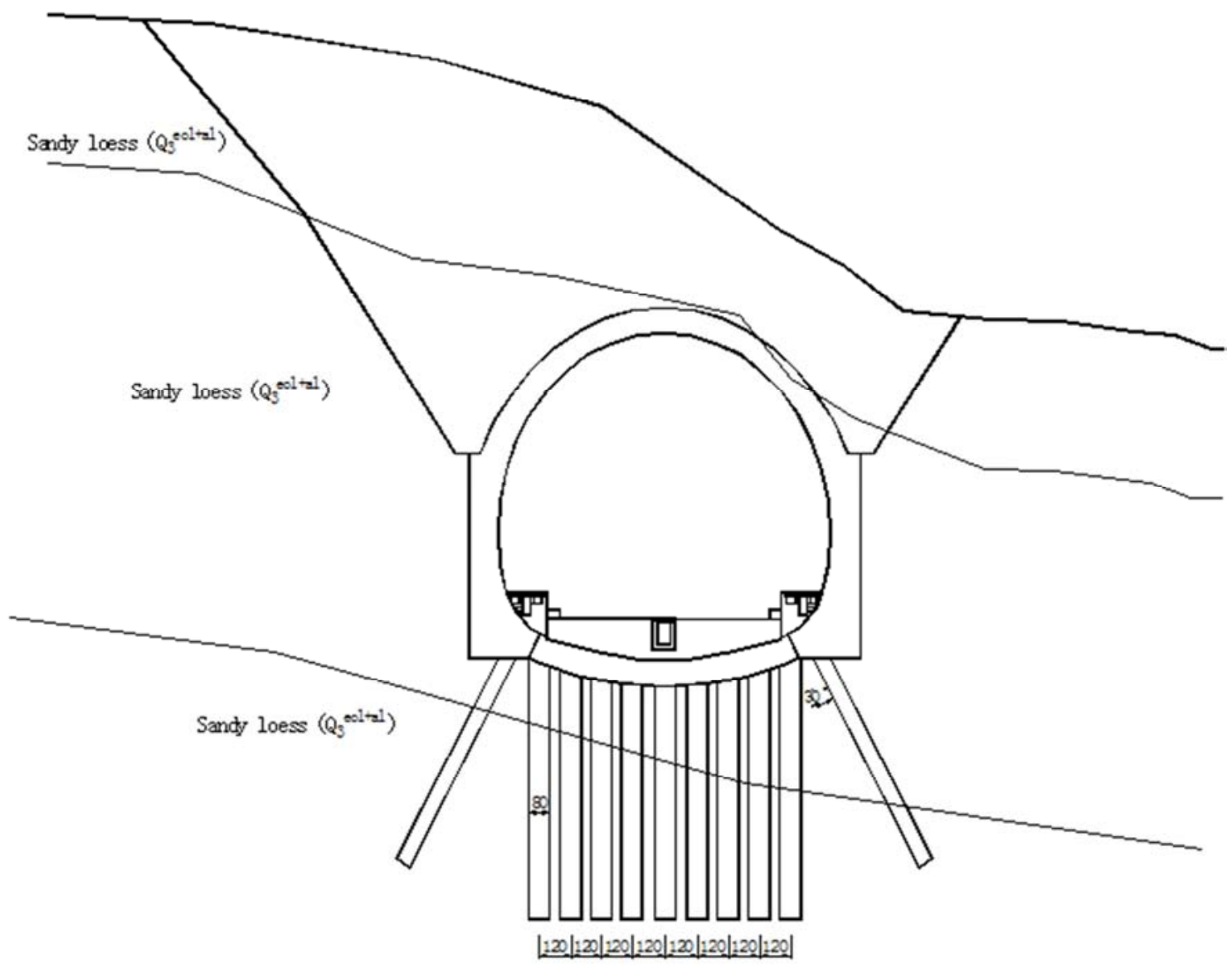

Figure 1. Schematic diagram of the reinforcement of the jet.

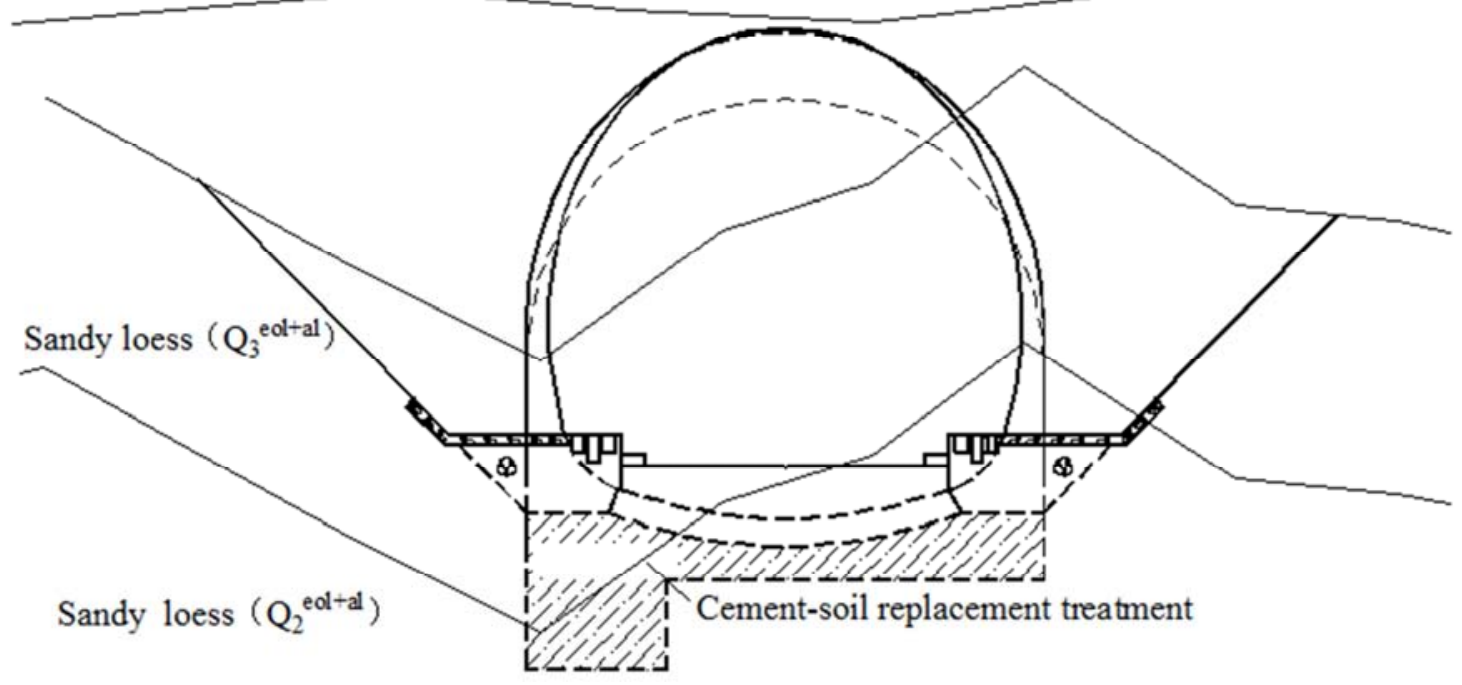

Figure 2. Schematic diagram of cement-soil replacement treatment at the entrance of Huanglongcun Tunnel.

The main advantages of using the replacement cushion method to reinforce the foundations of the collapsible loess tunnel are the low engineering cost and the simple construction process. But its shortcomings are also more prominent, that is, the treatment depth is shallow and the tunnel excavation section is increased during construction, which may weaken the bearing capacity of the arch foot. If the bottom of the tunnel is not closed in time, there will be bottom instability and reduce the overall stability of the tunnel. In addition, the tamping of the cushion layer also produces large 
vibrations, which causes certain hidden dangers to the construction safety of the tunnel. At the same time, the interaction with the tunnel construction is also relatively large.

\subsection{The Impact Compaction Method and Its Advantages and Disadvantages}

The impact compaction method is to use small hammers drive the foundation soil to be reinforced into a pile hole. The original soil in the pile hole is squeezed into the surrounding soil, and then lime soil, cement soil and other fillers was filled and impacted into the pile hole in layers.

According to the principle of lime-soil compaction piles, the cement-soil compaction piles have been researched and tested the collapsible loess tunnel foundations of the Fenghuangling Tunnel of Zhengzhou-Xi'an High-speed Railway. Firstly, a small hole was dumped by the self-made Luoyang shovel, and then the small hole was impacted and expanded to be a large hole, finally, cement, soil and other fillers were filled and impacted into piles.

The main advantages of impact compaction pile method are that it is relatively mature and economical. Its shortcomings are large construction vibration, more intersection with other processes, and higher requirements for initial support and so on. According to the on-site construction, vibration monitoring, and effect evaluation of the Zhengzhou-Xi'an High-Speed Railway on the lime-soil (cement-soil) impact compaction pile, it can be seen that the various indexes of the collapsible loess tunnel foundations can basically meet the specifications and designs after the adoption of impact compaction pile method. However, the actual measured wave speed of vibration during construction is about $5 \mathrm{~cm} / \mathrm{s}$ (Zhengzhou-Xi'an High-Speed Railway's datas), and the vibration safety requires a wave speed of $2 \sim 3 \mathrm{~cm} / \mathrm{s}$. Because the vibration is short-term and local, the Zhengzhou-Xi'an High-Speed Railway loess tunnel didn't experience a major collapse accident, but the lining cracking and falling blocks have occurred from time to time.

\subsection{The Root Pile Method and Its Advantages and Disadvantages}

The Root pile method refers to a reinforced concrete cast-in-place pile that uses auger drilling to form holes, and uses reinforcement and pressure grouting to form piles. It can be arranged in a vertical or oblique manner to form a cross network similar to the shape of tree roots. The pile is called the Root Pile Method [2].

In the construction of Zhengzhou-Xi'an High-Speed Railway, tunnel foundations were treated with tree root piles such as the Hanguguan Tunnel, Tongluochuan Tunnel, and Xinxingshumao. The Root Pile Method has the advantages of simple construction equipment, high construction safety, and small operation space and so on. But there are also some shortcomings such as the limited scope of reinforcement of single root piles, the difficulty of controlling and testing the overall reinforcement effect, and the limitation on the depth of reinforcement at the same time.

\section{Research and Development of New Non-vibration Compaction Technology}

In order to meet the special requirements of the reinforcement treatment of collapsible loess foundations of high-speed railway tunnels, according to the actual situation of the site and the structural and physical characteristics of the loess layer, the adopted reinforcement treatment technology should consider no vibration or vibration controlling, eliminate collapsibility, and improve bearing capacity, no grout pollution or additional collapsible deformation and other factors. Based on the situations, the researchers of China Railway Northwest Research Institute have been committed to long-term research on the miniaturization and non-vibration compaction processing technology since 2010. After long-term unremitting efforts, we have successfully developed the "Non-vibration Treatment Technology for Collapsible Loess Tunnel Basemet" and developed a non-vibration compactor and non-vibration compaction machine and so on, and finally obtained 3 national invention patents and 6 utility model patents.

\subsection{Basic Composition and Characteristics of Non-vibration Compactor}

1) Basic composition of the non-vibration compactor

The non-vibration compactor developed by the researchers of China Railway Northwest Research Institute is mainly composed of four parts: the power part, the correction part, the soil squeezing part, the opening and the guide part [10]. The shape is cone-shaped, as shown in Figure 3.

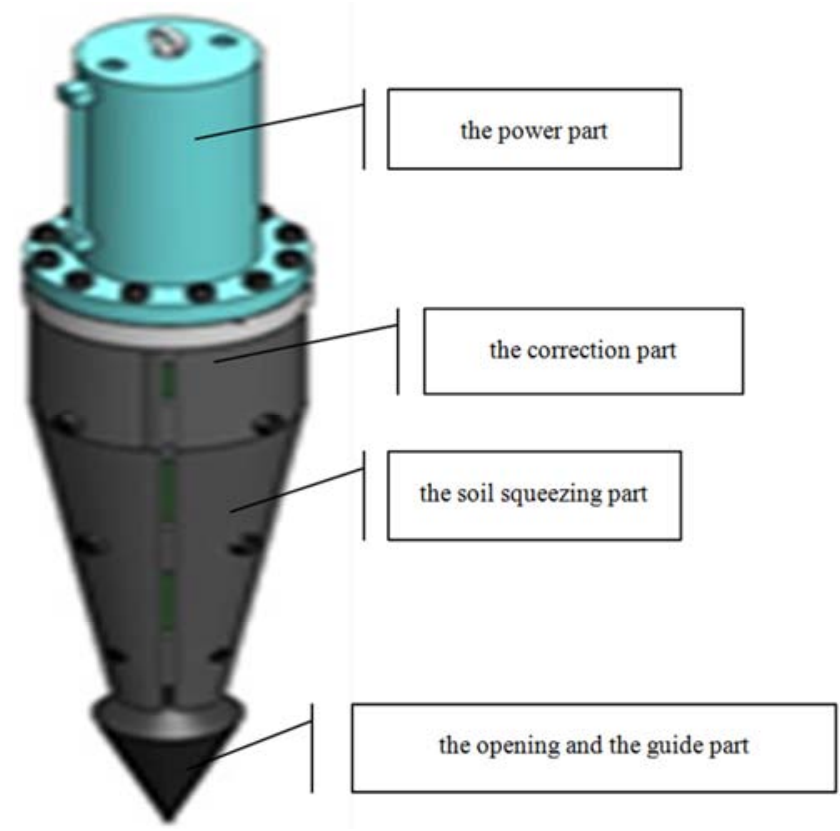

Figure 3. Composition diagram of the non-vibration compactor.

2) The force characteristics of the non-vibration compactor In the process of squeezing and reaming the soil, the non-vibration compactor was received the reaction force mainly composed of three parts [10], as shown in Figure 4. 


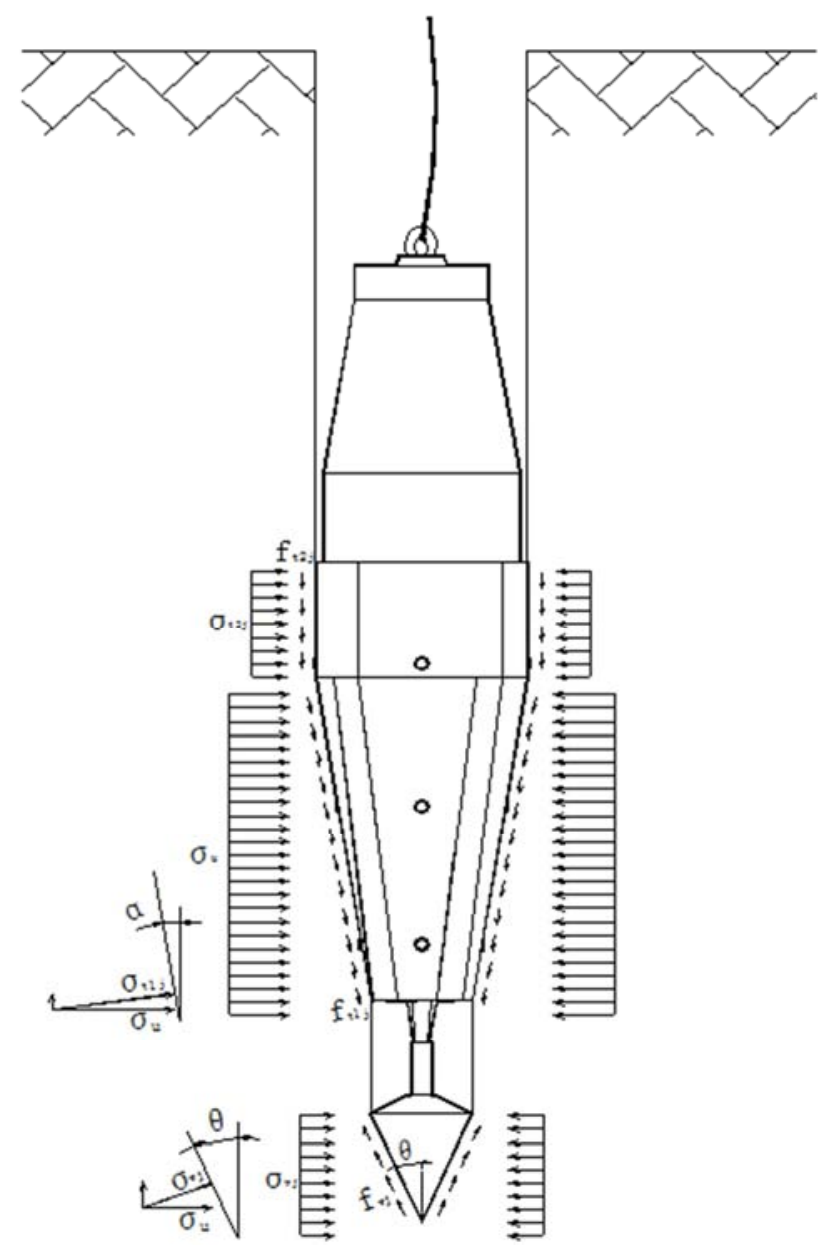

Figure 4. Schematic diagram of force state of the non-vibration compactor.

According to the force principle of the static compaction pile, the formula of the vertical reaction force $\mathrm{F}_{v j}$ of the non-vibration compactor can be obtained as follows:

$$
\begin{gathered}
F_{v j}=\left(\sigma_{v j} \cdot \sin \theta \cdot S_{v j}+f_{v j} \cdot \cos \theta \cdot S_{v j}\right)+\left(\sigma_{t 1 j} \cdot \sin \alpha \cdot S_{t 1 j}-\right. \\
\left.f_{t 1 j} \cdot \cos \alpha \cdot S_{t 1 j}\right)
\end{gathered}
$$

In the formula:

$\theta$ - the angle between the generatrix of the guide part and the axis;

$S_{v j}$ the side area of the guide part;

A — the angle between the squeezing part and the axis;

$S_{t l j}$ the side area of the soil extruding part.

There have been many research methods on the squeezing effect of static pile driving on soil and its mechanism [11], among which the most commonly used are the small hole expansion theory and the limit equilibrium theory.

In the analysis of the force characteristics of the compactor, the values of the parameters as follows: the radius of the bottom surface of the guide part is $d_{j t z}=0.1 \mathrm{~m}$, the length of the generatrix $l_{j t z}=0.26 \mathrm{~m}$, the angle between the generatrix and the center line is $\theta=22.5^{\circ}$; the maximum radius of the lower platform $r_{1}=0.205 \mathrm{~m}$, the maximum radius of the lower platform $r_{2}=0.20 \mathrm{~m}$, the length of the generatrix $l=0.74 \mathrm{~m}$, and the angle between the generatrix and the centerline $\theta=8.5^{\circ}$.

The physical and mechanical parameters of soil mass were taked by Lanzhou undisturbed collapsible loess as an example and refered to related literature $[12,13]$. The values are as follows:

(1) Cohesion $C=16 \mathrm{kPa}$;

(2) The internal friction angle $\varphi=31.1^{\circ}$;

(3) Poisson's ratio $\mu=0.25$;

(4) Compression modulus $E_{\mathrm{s}}=4.2 \mathrm{MPa}$;

(5) Deformation modulus $E_{0}=4.9 \mathrm{MPa}$;

(6) The density is $\rho=1.46 \mathrm{~g} / \mathrm{cm}^{3}$, and the weight $\gamma=14.4 \mathrm{kN} / \mathrm{m}^{3}$;

(7) This calculation depth $\mathrm{H}=8.0 \mathrm{~m}$.

After analyzing and calculating the force characteristics of the non-vibration confidential device by using the small hole expansion theory and the limit equilibrium theory, it is obtained: when the diameter of the compacted hole reaches $0.41 \mathrm{~m}$, the force applied by the non-vibration compactor to squeeze the soil is $903 \mathrm{kN}$, the vertical force of the power part is $231 \mathrm{kN}$.

\subsection{Basic Composition and Characteristics of Non-vibration Compaction Machine}

To make sure the non-vibration compactor work properly, it is necessary to use the mobile system, hydraulic system, lifting system, support system, operating system and so on. In order to adapt to the requirements of different working conditions, scientific researchers have developed "combined non-vibration compaction machine", "separated non-vibration compaction machine".

1) Combined non-vibration compaction machine

The combined non-vibration compaction machine is a special construction equipment developed for small spaces or narrow sites such as collapsible loess tunnels in this project. The equipment assembles a small mobile device, lifting support system, hydraulic system, operating system, non-vibration compactor, etc. into a whole. Its dead weight is less than $3.5 \mathrm{t}$, length is $3.3 \mathrm{~m}$, height is $3.1 \mathrm{~m}$, width is $1.6 \mathrm{~m}$, and plane working radius is not less than $5 \mathrm{~m}$, as shown in Figure 5.

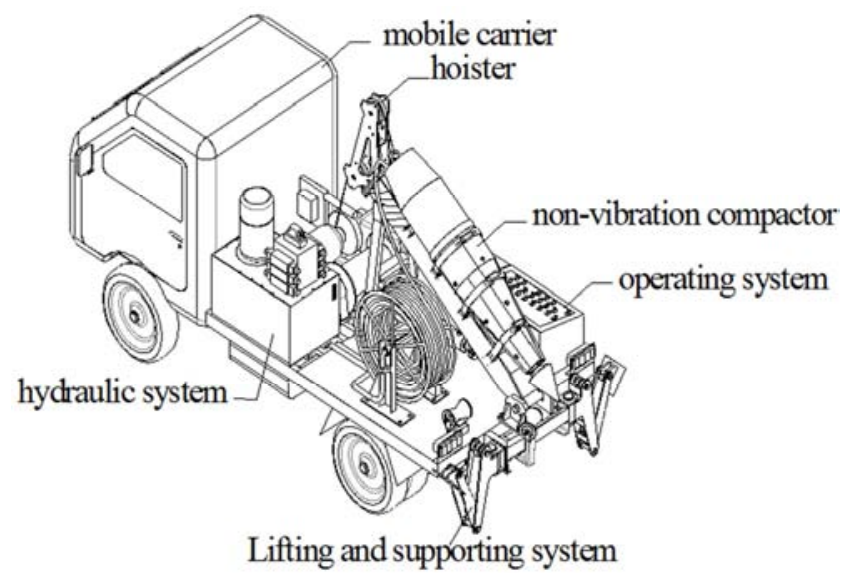

Figure 5. Composition diagram of the combined non-vibration compaction machine.

The combined non-vibration compaction machine can realize the fixed-point operation of the winch, hydraulic outriggers, and non-vibration compactor with only electronic 
control buttons. It is fully equipped with the performances of miniaturization, lightness, operability and mobility. The pore-forming rate of the surface loess layer is $0.2-0.3 \mathrm{~m} / \mathrm{min}$ and the pore-forming rate of the deep loess layer is $0.1-0.2 \mathrm{~m} / \mathrm{min}$ during normal construction operations.

2) Separated non-vibration compaction machine

The separated non-vibration compaction machine is developed to better adapt to the working conditions in small spaces such as tunnels and indoor houses. The separated non-vibration machine mainly separates the hydraulic and operating devices, the mobile and lifting device, and the non-vibration compactor completely. According to the actual needs of the site, the three parts are connected by hydraulic hoses, wire ropes, etc. to meet various requirements for the use of machine.

During the on-site movement of the non-vibration compactor, if the movement distance is long, the non-vibration compactor can be separated from the lifting and moving device, and moved to the designated position by means of power equipment or manual rolling; if the movement distance is short, the non-vibration compactor can be moved to the designated position. The vertical guide part of the non-vibration compactor can be moved to the ground, as shown in Figure 6.

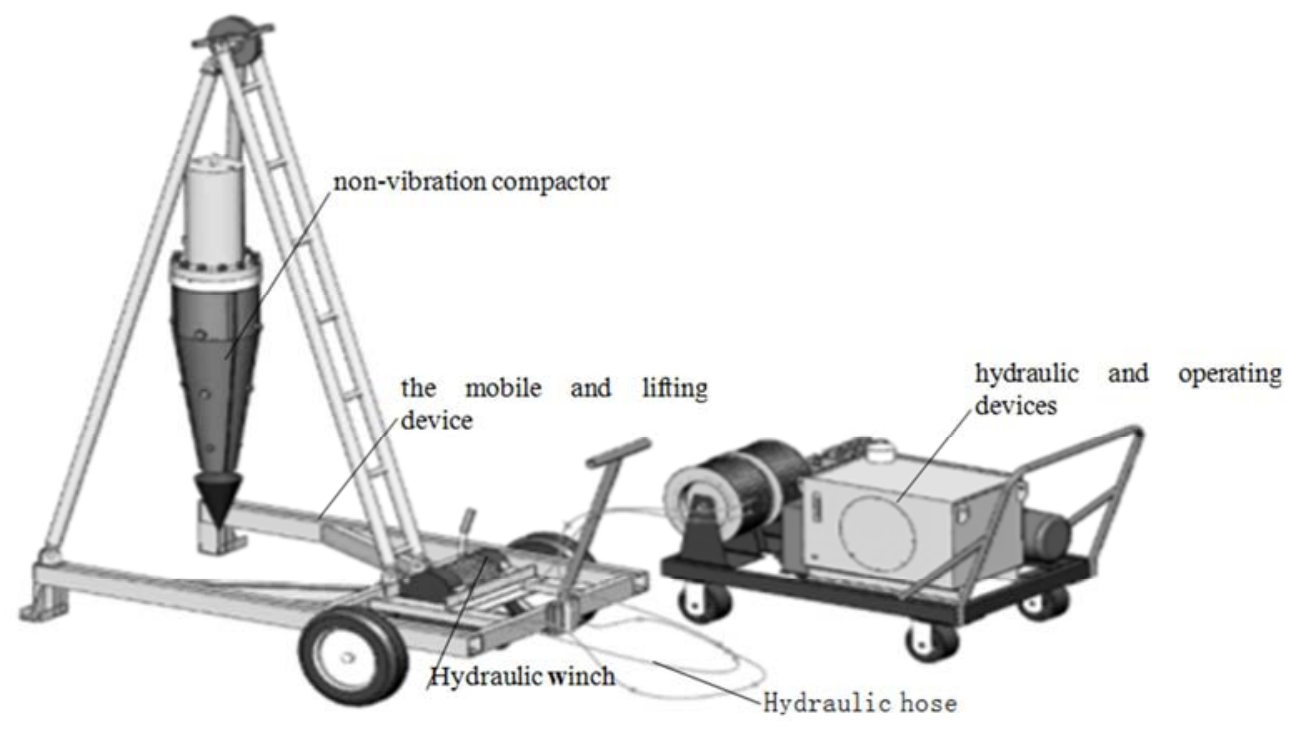

Figure 6. Composition diagram of the separated non-vibration compaction machine.

The separated non-vibration compaction machine has the characteristics of compactness, flexibility, practicality and reliability in the applicability test of the compaction treatment of the collapsible loess tunnel foundations. Under the normal working conditions, the pore-forming rate of the surface loess layer is $12-18 \mathrm{~m} / \mathrm{h}$, and the pore-forming rate of the deep loess layer is $6-12 \mathrm{~m} / \mathrm{h}$. Each component is operated by electronic control buttons, which can realize the fixed-point control of the winch system and the non-vibration compactor at the same time.

\section{Analysis on the Effect of Non-vibration Compaction and Reinforcement of Foundation}

In order to verify the adaptability and effectiveness of the non-vibration compaction processing technology and the non-vibration confidential machine and non-vibration compactor developed by the supporting equipment, researchers from China Railway Northwest Research Institute conducted an application test by working on the reinforcement of the collapsible loess tunnel foundations of the BaojiLanzhou High-Speed Railway Passenger Dedicated Line [13]. In the experiment, the pre-formed hole diameter of the non-vibration compaction hole is $\varphi=0.41 \mathrm{~m}$, and the pile spacing is respectively $\mathrm{S}_{1}=0.8 \mathrm{~m}, \mathrm{~S}_{2}=0.9 \mathrm{~m}, \mathrm{~S}_{3}=1.0 \mathrm{~m}, \mathrm{~S}_{4}=1.2 \mathrm{~m}$, as shown in Figure 7, each hole is adopted the method of squeezing the gaps into holes.

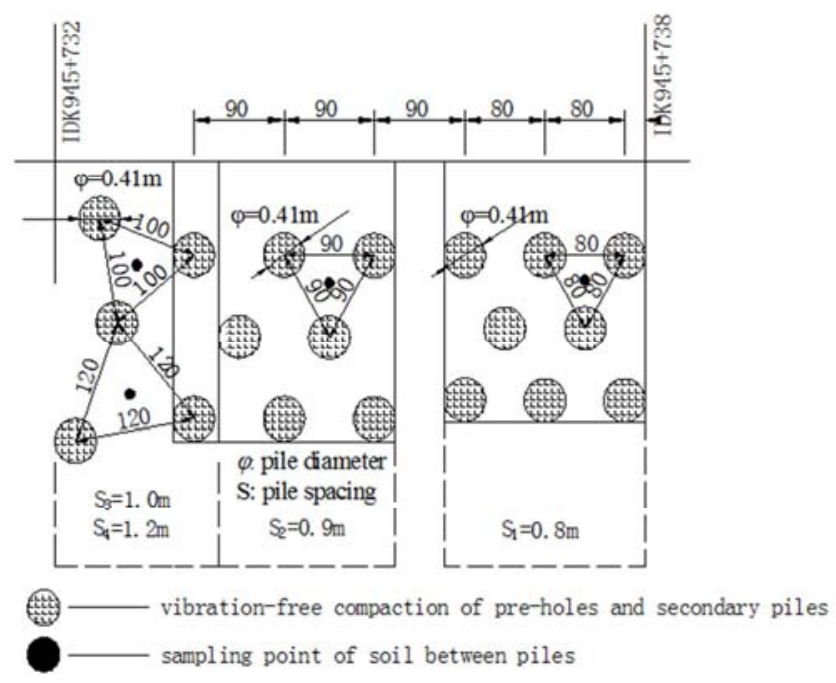

Figure 7. Layout drawing of reasonable pile spacing test in the open section of the tunnel (unit: centimeter).

The results show that the minimum compaction coefficient of the soil between the piles exceeds the specification (GB 
50025-2004)[14], "Railway Engineering Foundation Treatment Technical Regulations (TB 10106-2010, J 1078-2010)[15], the results stipulate the requirement of not less than 0.88 , and the average compaction coefficient of the soil between the piles is greater than or equal to 0.93 specified in the literature [14] and the literature [15] of relevant requirements greater than or equal to 0.90 . When the pile spacing $\mathrm{S}_{3}=1.0 \mathrm{~m}, \mathrm{~S}_{4}=1.2 \mathrm{~m}$, and both failed to meet the specific requirements of the corresponding specifications [14, 15], as shown in Figure 8.

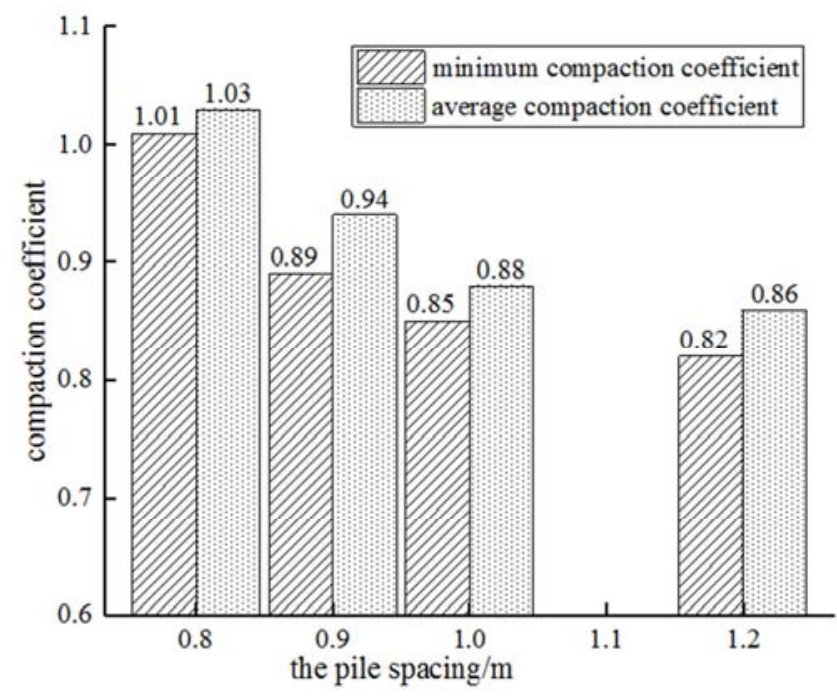

Figure 8. Diagram of Soil compaction coefficient between pile.

The changes in the collapsibility of the soil between the piles under different pile spacing conditions are as follows:

(1) When the pile spacing $\mathrm{S}_{1}=0.8 \mathrm{~m}$, the collapsibility coefficient and the self-weight collapsibility coefficient both are 0.000 0.001, which is less than 0.015;

(2) When the pile spacing $\mathrm{S}_{2}=0.9 \mathrm{~m}$, the collapsibility coefficient and the self-weight collapsibility coefficient both are $0.000 \sim 0.002$, which is less than 0.015 ;

(3) When the pile spacing $\mathrm{S}_{3}=1.0 \mathrm{~m}$, the collapsibility coefficient and the self-weight collapsibility coefficient both are $0.000 \sim 0.001$, which is less than 0.015 ;

(4) When the pile spacing $\mathrm{S}_{4}=1.2 \mathrm{~m}$, the collapsibility coefficient is $0.002 \sim 0.005$, and the self-weight collapsibility coefficient is $0.002 \sim 0.009$, both of which are less than 0.015 .

It can be seen from table 1 that the collapsibility of the loess foundation is completely eliminated after the collapsible loess tunnel was reinforced by non-vibration static pressure compaction under the conditions of the pile diameter $\varphi=0.41 \mathrm{~m}$ and the pile spacing $\mathrm{S}$ is $0.8 \sim 1.2 \mathrm{~m}$ for the Baoji-Lanzhou High-Speed Railway Passenger Dedicated Line.

Table 1. Hanges of soil collapsibility coefficient between piles.

\begin{tabular}{llllll}
\hline \multirow{2}{*}{ different coefficient } & & \multicolumn{5}{c}{ the pile spacing S/m } \\
\cline { 3 - 6 } & & $\mathbf{0 . 8}$ & $\mathbf{0 . 9}$ & $\mathbf{1}$ & $\mathbf{1 . 2}$ \\
\hline \multirow{2}{*}{ collapsibility coefficient } & minimum & 0.001 & 0.000 & 0.000 & 0.002 \\
\cline { 2 - 6 } self-weight & maxmum & 0.001 & 0.002 & 0.001 & 0.005 \\
collapsibility coefficient & minimum & 0.001 & 0.000 & 0.000 & 0.002 \\
\cline { 3 - 6 } & maxmum & 0.001 & 0.002 & 0.001 & 0.009 \\
\hline
\end{tabular}

\section{Conclusions}

(1) The selection of the tunnel foundation reinforcement scheme in the collapsible loess area should be mainly considered the treatment principles, treatment effects, construction space, construction procedures, vibration controlling requirements and other factors to be comprehensively determined. Single or combined measures such as tree root piles, replacement cushions, jet grouting piles, and impact compaction piles may be adopted.

(2) The developed new technology and new equipment for non-vibration compaction machine are suitable for the reinforcement treatment of the collapsible loess tunnel foundations. It has the advantages of convenient movement, controllable treatment effect, miniaturization, and low cost.

(3) Through the field test of the tunnel foundation treatment of the Baoji-Lanzhou High-Speed Railway Passenger Dedicated Line, the advancement and operability of the new technology of non-vibration compaction treatment was verified. At the same time, it provides a new technology and new method for the foundation treatment of the narrow space and strict controlling of the construction vibration in loess tunnels, which has good application prospects.

\section{Contributors}

ZHAO Yong-hu provided the concept and edited the draft of manuscript. Others conducted the literature review and wrote the first draft of the manuscript. All authors replied to reviewers' comments and revised the version.

\section{Conflict of Interest}

The authors declare that they have no conflict of interest.

\section{Foundation Item}

Projects (51868038) supported by the National Natural Science Foundation of China; Key scientific research projects (2018-emphasis-45) supported by China Railway Group Limited; Scientific research projects (2018-KJ008-Z008-XB) supported by China Railway Scientific Research Institute Co., Ltd.

\section{References}

[1] WANG X D. Treatment technology of collapsible loess tunnel basement on Zhengzhou-Xi'an Railway Passenger Dedicated Line [J]. Railway Standard Design, 2007 (S1): 90-92.

[2] LIU D G, WANG M N, PANG L X. Field test study on root pile of foundation base in loess tunnel [J]. Hydrogeology \& Engineering Geology, 2008 (02): 120-123.

[3] LI L. Study on strengthening technology used in tunnel foundation base of Ballasstless-track Heavy-haul Railway [J]. Railway Standard Design, 2014, 58 (05): 95-99. 
[4] FU W. Distribution rules of collapsible loess and analysis on foundation treatment technology on Baoji-Lanzhou Passenger Dedicated Line [J]. Railway Standard Design, 2014, 58 (11): 15-19.

[5] FAN W, SHAO S J, YANG CH M, et al. Method for calculating collapsible compressive stress of loess tunnel foundation [J]. Chinese Journal of Geotechnical Engineering, 2015, 37 (S2): 80-85.

[6] LI G L, SHAO SH J, JIN B C, et al. Research on the problems of collapsibility of loess tunnel foundation [J]. Journal of Railway Engineering Society, 2015, 32 (12): 12-16+50.

[7] CHEN F J, LIU J G, FANG Q B, et al. stability research of loess tunnel subsoil reinforced by cement soil compaction piles [J]. Railway Engineering, 2017 (07): 85-87.

[8] SUN B. Application of non-vibration compaction technology of foundation treatment in collapsible loess tunnel [J]. Railway Engineering, 2017 (03): 70-72.

[9] WANG X ZH, et al. Construction technology of large section loess tunnel [M]. Beijing: China Railway Press, 2009.

[10] MI W J, JIA Y, QU Y H, et al. Research on the stress characteristics of transverse static pressure with compaction technology on loss foundation [J]. Journal of Railway Engineering Society, 2016, 33 (1): 16-51.

[11] TANG SH D, LI Y. Analysis on consolidation mode in saturated clayed soil foundation around pile and its solution by progression [J]. Site Investigation Science and Technology, 2005 (03): 3-6+25.

[12] LI B X, NIU Y H, MIAO T D. Physico-mechanical characteristics of Malan loess in Lanzhou region [J]. Rock and Soil Mechanics, 2007, 28 (6): 1077-1082.

[13] MI W J, JIA Y, JIA Y, et al. Exploration on the compaction effect of static pressure in foundation of loess tunnel of Baoji Lanzhou Passenger Dedicated Line [J]. Journal of Railway Engineering Society, 2015 (11): 98-19.

[14] National Standard of the People's Republic of China. Building Code for Collapsible Loess Area (GB50025-2018) [S]. Beijing: China Construction Industry Press, 2018.

[15] Ministry of Railways of the People's Republic of China. Technical Regulations for Foundation Treatment of Railway Engineering (TB 10106-2010) [S]. Beijing: China Railway Publishing House, 2010. 